\title{
The Measuring Ammonia in Nature (MAN) network in the Netherlands
}

\author{
D. E. Lolkema, H. Noordijk, A. P. Stolk, R. Hoogerbrugge, M. C. van Zanten, and W. A. J. van Pul \\ National Institute for Public Health and the Environment (RIVM), Bilthoven, the Netherlands \\ Correspondence to: D. E. Lolkema (dorien.lolkema@rivm.nl)
}

Received: 12 March 2015 - Published in Biogeosciences Discuss.: 24 April 2015

Accepted: 12 August 2015 - Published: 31 August 2015

\begin{abstract}
Since 2005 the Measuring Ammonia in Nature (MAN) network monitors atmospheric ammonia concentrations in nature reserve areas in the Netherlands (http://man. rivm.nl). The main aim of the network is to monitor national trends, to assess regional deviations and to validate model calculations. Measurements are performed with commercial passive samplers, calibrated monthly against ammonia measurements of active sampling devices. The sampling is performed by an extensive group of local volunteers, which minimizes the cost and enables the use of local knowledge. We show the MAN network to be well capable of monitoring trends on national and local scales and providing data for more detailed local analyses. The quality of the network is such that trends over time for individual MAN areas can be detected on the order of $3 \%$ per year for time series of 6-9 years.
\end{abstract}

\section{Introduction}

High levels of nitrogen have harmful effects on sensitive ecosystems, i.e. they lead to a loss in biodiversity. In the Netherlands, nitrogen deposition levels are high, making it one of the issues to be addressed in halting biodiversity loss. To preserve the ecological value of nature areas, several nature areas have been designated as Natura2000 areas (Natura2000, 2015). These areas fall under the Birds Directive and the Habitats Directive (European Commision, 1992, 2009) and need to be protected under European legislation. In the Netherlands, 117 out of the 166 Natura2000 areas are sensitive to nitrogen input (PAS, 2015).

The total nitrogen deposition is the sum of several components and consists of both dry and wet deposition. Key to the total nitrogen deposition in the Netherlands is the dry deposition of ammonia with a contribution of around $45 \%$. When focusing on national sources, $60 \%$ of the nitrogen deposition comes from dry deposition of ammonia (Velders et al., 2010). Due to its large spatial variability and difficulty of measurement it is hard to assess the dry deposition of ammonia for all Natura2000 areas. However, atmospheric concentrations of ammonia are much easier to measure as is done in the Dutch Monitoring Air Quality Network (LML; Landelijk Meetnet Luchtkwaliteit). Concentrations are measured with the $\mathrm{AMOR}^{1}$ (van Elzakker, 2001) measuring device continuously at six locations. Expansion of the LML network to monitor the ammonia levels at a large number of nature areas is not feasible for financial and practical reasons.

For an accurate estimate of atmospheric ammonia concentrations in Natura2000 areas, the Measuring Ammonia in Nature (MAN) network was established. In this network passive samplers provide monthly values of the atmospheric ammonia concentration. The focus of the network is on the Natura2000 areas that are sensitive to nitrogen input.

We will show that the MAN network is well capable of providing accurate atmospheric ammonia concentrations in nature areas. With this network we are able to establish trends, assess regional deviations and investigate the effects of changes in emission sources on a local scale. The ammonia concentrations are also used for validation of the model calculations with the OPS model (Operational Priority Substances; van Jaarsveld, 2004).

In this paper, we start with a description of the MAN network and an explanation of the measuring method. Calibration and validation procedures are explained in detail, leading

\footnotetext{
${ }^{1}$ The AMOR device was replaced by the DOAS (Differential Optical Absorption Spectroscopy) device in 2015.
} 


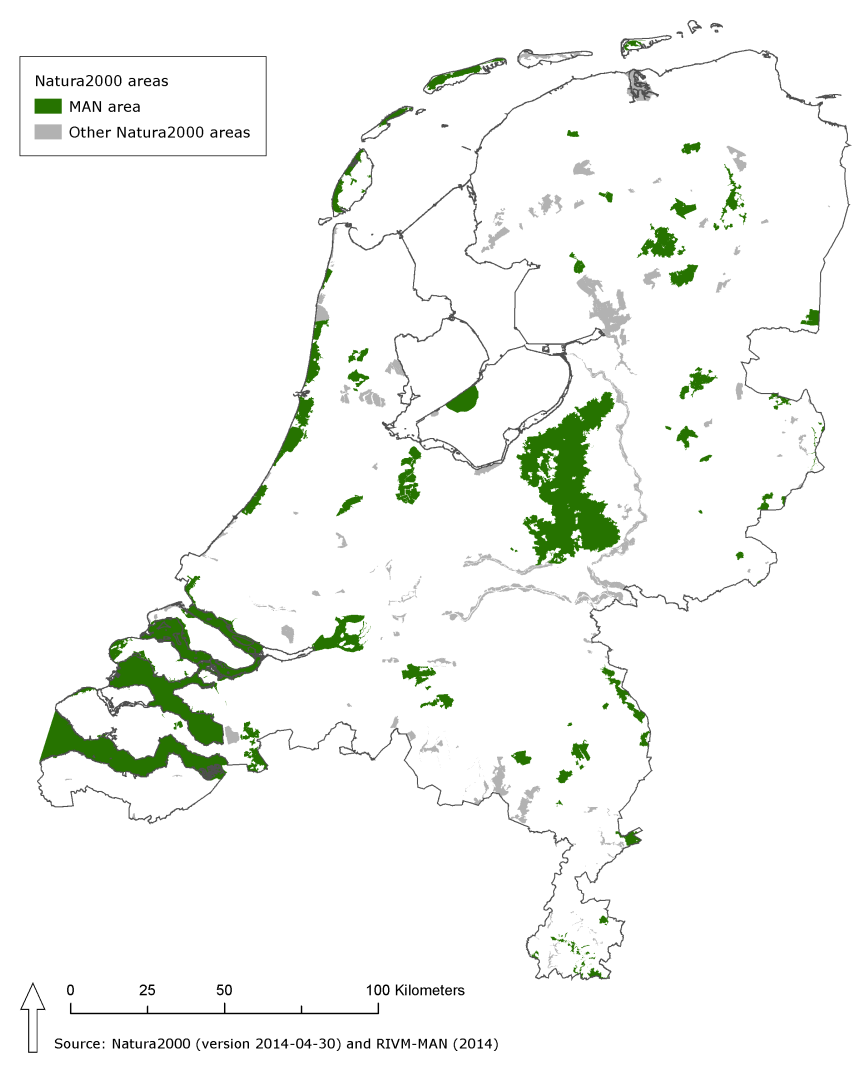

Figure 1. The MAN network in 2014.

to an estimate of the accuracy. Results on national, regional and local scales are presented and the paper ends with the conclusion.

\section{Description}

The MAN network aims to monitor the atmospheric ammonia concentrations in Natura2000 areas. Due to the large spatial variability of ammonia concentrations, a lot of sampling points are needed. Therefore, we monitor the concentration using a low cost measuring device, i.e. passive samplers (Gradko, 2015). Passive samplers are common to monitor atmospheric ammonia concentrations (van Pul et al., 2004; Thöni et al., 2003; Dämmgen, 2007; Carmichael et al., 2003; Puchalski et al., 2011; Wilson and Serre, 2007; Zbieranowski and Aherne, 2013). The three main reasons to select this type of samplers are (i) they are inexpensive; (ii) they are small and can be used without extra housing, which makes them inconspicuous and reduces the change of sabotage of the measurements; and (iii) they are easy to handle which is a major advantage for the monthly exchange by volunteers in the field. On the other hand, individual passive samplers do have a large uncertainty in the determined ammonia concentration. However, with a good measurement strategy and quality as-

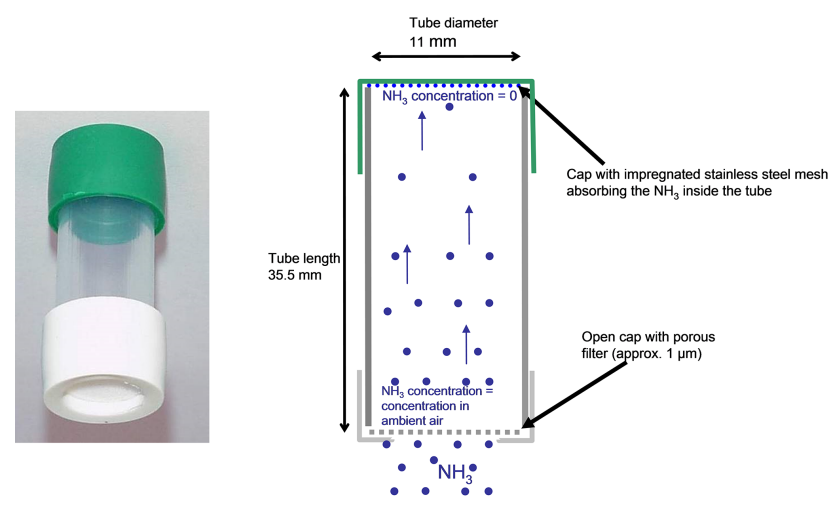

Figure 2. The ammonia passive sampler from Gradko, as exploited in the MAN network.

surance and -control this uncertainty is significantly reduced. This will be explained in detail in Sects. 3.1, 3.2 and 3.4.

The MAN network started with 22 Natura2000 areas in 2005 and has been expanded several times since then. Areas are selected for their sensitivity to nitrogen deposition. The network aims to be representative of different habitat types, ammonia concentration levels, area size and shape, as well as the geographical distribution. In 2014, the network contained 60 Natura2000 areas with a total of 236 sampling points. Figure 1 gives an overview of the MAN network.

Each measurement area contains at least two sampling points with an average of four per measurement area. For most small areas, the objective is to determine the ammonia concentration that is characteristic for that area. For larger areas, sampling locations are selected to serve specific aims, such as to detect the spatial pattern in concentration or to assess the influence of local sources (agriculture activities but also traffic). Since September 2011 each area contains at least one triplicate measurement.

\section{Method}

The MAN network provides monthly mean values of the ammonia concentrations. Each month, the passive samplers are exchanged by local volunteers in the field, mostly nature rangers. A schematic view of the passive samplers is given in Fig. 2. The top end of the tube is impregnated with an acid which transforms $\mathrm{NH}_{3}$ to $\mathrm{NH}_{4}^{+}$, resulting in a net $\mathrm{NH}_{3}$ concentration of zero. In this way an ammonia gradient between the top end of the tube and the ambient concentration of $\mathrm{NH}_{3}$ is established. The bottom end is provided with a porous filter to minimise the effect of turbulence. The bottom end is open during exposure and sealed with a protective cap when not exposed. Exposed tubes are analysed in the laboratory by Gradko where the total ammonium concentration is determined. With the tube dimensions and the diffusion coefficient, the total ammonia concentration is calculated. The volunteers register the moment of sample exchange enabling 


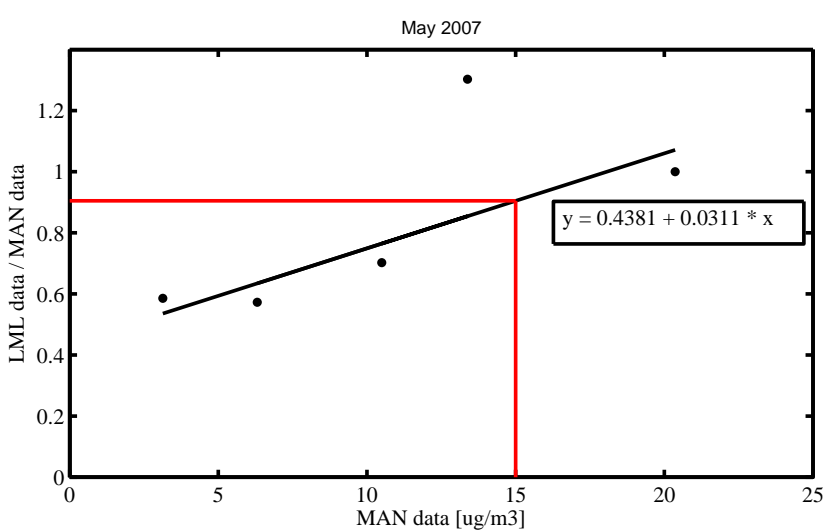

Figure 3. Example of the monthly calibration for the month of May in 2007. Displayed is the LML/ MAN ratio against the MAN data. The black line gives the regression. The red line indicates that the correction factor for a measured value of $15 \mu \mathrm{g} \mathrm{m}^{-3}$ ammonia is 0.9 for the month of May in 2007.

a precise calculation of the exposure time and the monthly mean ammonia concentration.

The diffusion coefficient depends on meteorological conditions, mostly the ambient temperature. This dependency is compensated for by our calibration procedure.

\subsection{Calibration}

The LML ammonia measurements are used to calibrate the passive sampler measurements. Each month sets of three passive samplers (triplicates) are placed at five LML stations and from January 2009 onwards at six LML stations that represent a wide range $\left(1-16 \mu \mathrm{g} \mathrm{m}^{-3}\right)$ of atmospheric ammonia concentrations. To determine the calibration parameters, the ratio between the LML concentration and the mean of the triplicate is determined for each LML station. After that, a linear regression is performed on the $5 / 6$ ratios against the triplicate means (Eq. 1). Then, the determined calibration parameters are applied to the non-calibrated passive samplers (see Fig. 3).

$y=a+b \cdot x$,

where $y$ is concentration (LML) divided by concentration (passive sampler), and $x$ is concentration (passive sampler).

Due to variations in exposure conditions the calibration parameters $a$ and $b$ are not constant and need to be determined each month. Figure 4 (top) shows the course of the values for $a$ and $b$ and the deviance of the fit from the beginning of the MAN network. After some problems during the first 2 years of operation, the deviance of the fit is now small, and the calibration parameters stabilise at an average of 0.6 for $a$ and at an average of 0.02 for $b$ (Fig. 4, bottom). Table 1 gives some examples of calibration when the average values of 0.6 for $a$ and 0.02 for $b$ apply. Notice that the effective calibration factor slowly increases for higher concentrations.
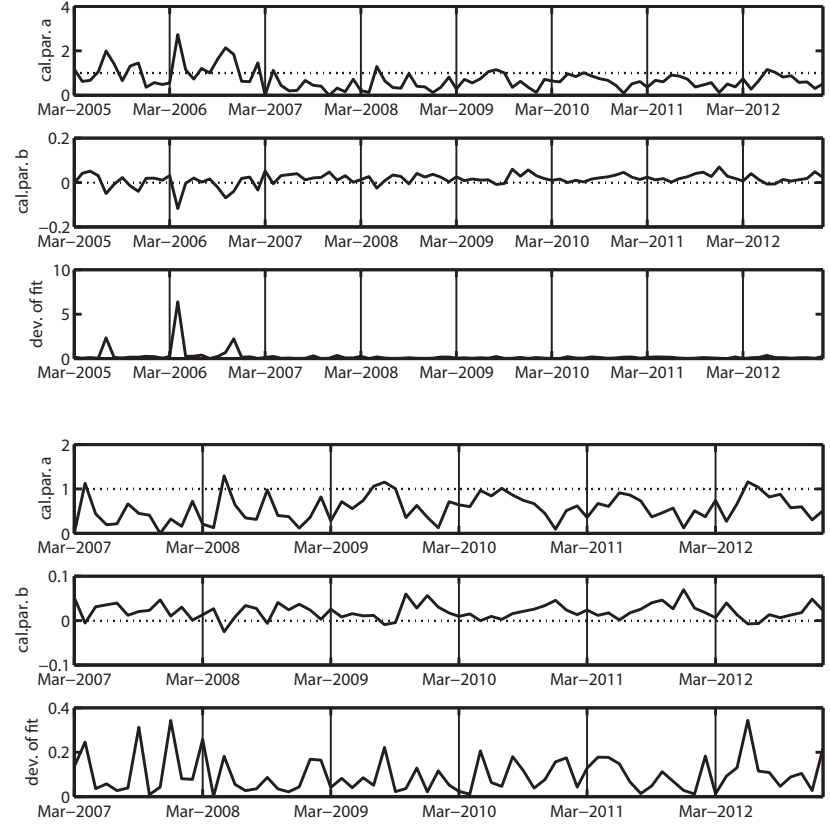

Figure 4. Calibration parameters $a$ and $b$ and the deviance of the fit for the period from March 2005 (top)/March 2007 (bottom) to January 2013.

Table 1. Typical effective calibration factors.

\begin{tabular}{lrr}
\hline $\begin{array}{l}\text { Non-calibrated } \\
\mathrm{NH}_{3} \text { value }\end{array}$ & $\begin{array}{r}\text { Calibrated } \\
\mathrm{NH}_{3} \text { value }\end{array}$ & $\begin{array}{r}\text { Effective } \\
\text { calibration factor }\end{array}$ \\
\hline 0.10 & 0.06 & 0.60 \\
0.20 & 0.12 & 0.60 \\
0.50 & 0.31 & 0.61 \\
1.00 & 0.62 & 0.62 \\
2.00 & 1.28 & 0.64 \\
5.00 & 3.50 & 0.70 \\
10.00 & 8.00 & 0.80 \\
20.00 & 20.00 & 1.00 \\
\hline
\end{tabular}

Calibration parameter $a$ seems to present a yearly periodicity. To check this, we performed a Fourier analysis for both calibration parameters $a$ and $b$. With this analysis, prevailing frequencies in the data, if existing, become apparent. Indeed, the yearly periodicity $\left(10^{0}\right.$ years $=1$ year $)$ in calibration parameter $a$ becomes clear, as can been seen in Fig. 5, top right panel. For calibration parameter $b$, this periodicity is far less present. This same periodicity is slightly present in the standard deviation (SD) of the triplicates employed in the MAN. The ambient temperature is a likely candidate to cause this periodicity for it influences the diffusion process. Analysis of the monthly averaged temperature for De Bilt, the Netherlands gives a linear correlation coefficient of 0.53 . With 71 data pairs used, this is highly significant.

The ammonia concentration for areas in the vicinity of others will, by absence of local sources, follow the same 

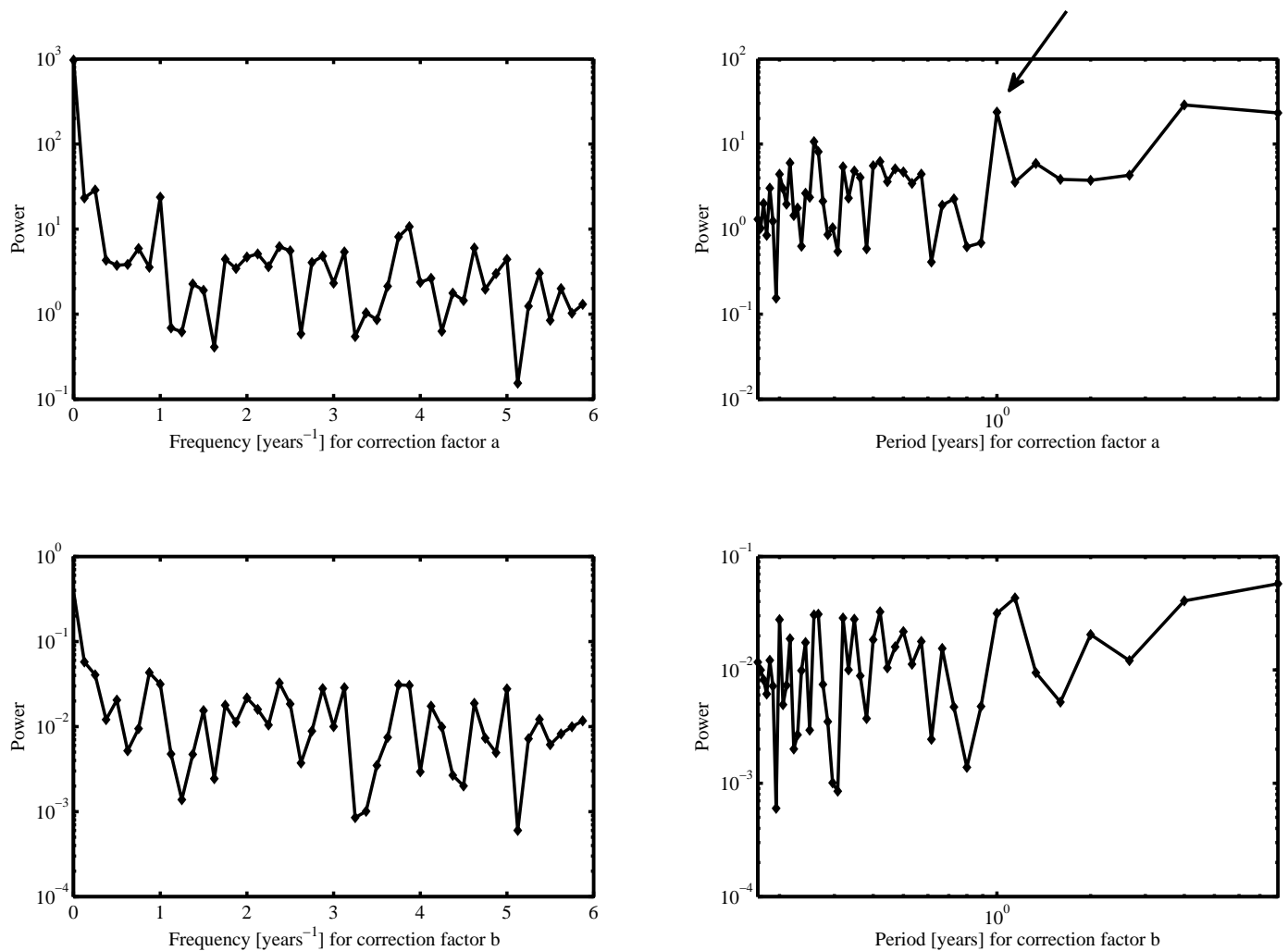

Figure 5. Frequency analysis of calibration parameters $a$ and $b$. Calibration parameter $a$ shows a distinct periodicity of 1 year, indicated with the arrow in the top right panel. Note the different $y$ scales for the different panels.
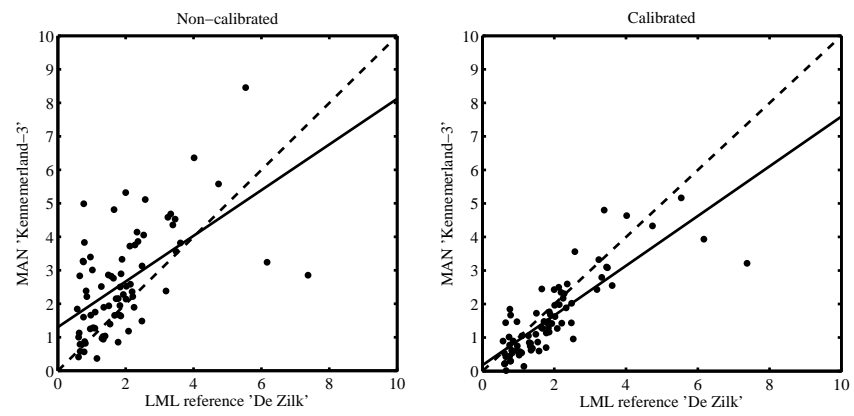

Figure 6. Example 1 of calibration effect on the data.

pattern. Therefore, passive sampler ammonia measurements taken in the vicinity of LML reference ammonia measurements should, by absence of local sources, follow the same pattern. This correlation should be higher for calibrated measurements than for non-calibrated measurements as long as the calibration procedure increases accuracy. The ammonia concentration in the dune areas Meijendel, Zwanenwater, Kennemerland and Voornes duin will likely follow the same pattern as the ammonia concentration at the LML reference station De Zilk. The ammonia concentration in the north-eastern areas Drentsche Aa and Dwingelderveld will likely follow the same pattern as the ammonia concentration
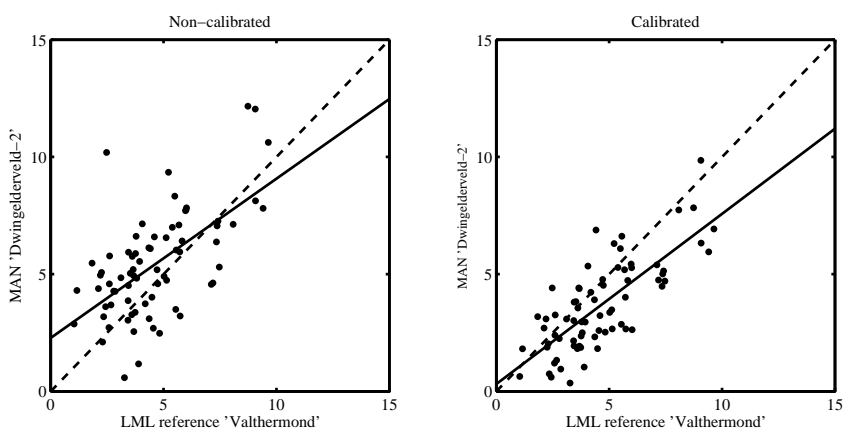

Figure 7. Example 2 of calibration effect on the data.

at the LML reference station Valthermond. Comparing the non-calibrated and calibrated data from these areas with data from the reference stations indeed shows an increase in correlation. Figures 6 and 7 provide two examples.

\subsection{Validation}

After calibration, all data are validated. This is a three-step process, performed yearly. Step 1: measurements can be compromised by incorrect handling like damage, falling on the ground, bird droppings, etc. The volunteers in the field as well as the employees at both RIVM (National Institute 
for Public Health and the Environment) and Gradko all can make remarks for each individual passive sampler. Validation codes will be applied for the concerning measurements. In step 2, every measurement will be checked for its SD of the whole time series for this sampling point. Measurements with a SD of more than $3 \sigma$ within the whole time series will be marked. Step 3 involves visual inspection of each measurement with the measurements taken in the same area and in similar areas. If a measurement value deviates from the others with no plausible explanation, a validation code will be applied. Information on meteorological conditions and area specifications will be taken into account for this decision. The triplicate measurements at the LML locations, used for calibration, are validated prior to calibration.

After this three-step process, usually a couple of dispute measurement values remain. These are discussed by a group of three experts. Validation codes will always remain visible, making analyses for different validation codes and reevaluation after new insights possible.

Over the years 2005-2013, 91.6\% of the measurements provided valid data, $6.5 \%$ of the data was rejected and $1.9 \%$ received the mark "suspicious". Suspicious data is not entirely trusted but decisive arguments to reject it are missing. For general analyses, suspicious data are treated as valid data.

\subsection{Missing data}

The atmospheric ammonia concentration follows a seasonal pattern throughout the year. Having a maximum of only twelve ammonia concentration values per year, already one missing value can change the calculated yearly average. Therefore, we apply an imputation method to gap-fill missing data. For the imputation of missing data in de MAN data set, the multiple imputation algorithm by Geman and Geman (1984) is used. Any missing value is replaced by a model value. However, instead of the model value itself, a random value from a normal distribution around the model value is drawn. The SD of this distribution is equal to the residual SD between the model and the measured values. This technique is implemented in the so-called Mimp tool of RIVM and tested on dioxin measurements (Hoogerbrugge and Liem, 2000). For the MAN data set, the following applies. (i) For the year under consideration, data of three consecutive years is used: the year before, the year itself and the year after. For the first year, the year itself and the two following years are used. For the last year, a temporary set is delivered using data from the year itself and the two previous years. (ii) Coastal locations and land locations are treated as separate sets. (iii) Log transformation and principal component regression of data are applied. (iv) In order to avoid negative values in the data set, a value of 1 is added to all data and subtracted afterwards. (v) More than 500 iterations are needed to reach convergence of the solutions. (vi) The gap-filling is performed in 10 independent imputation cycles using extremely different starting values and the median of

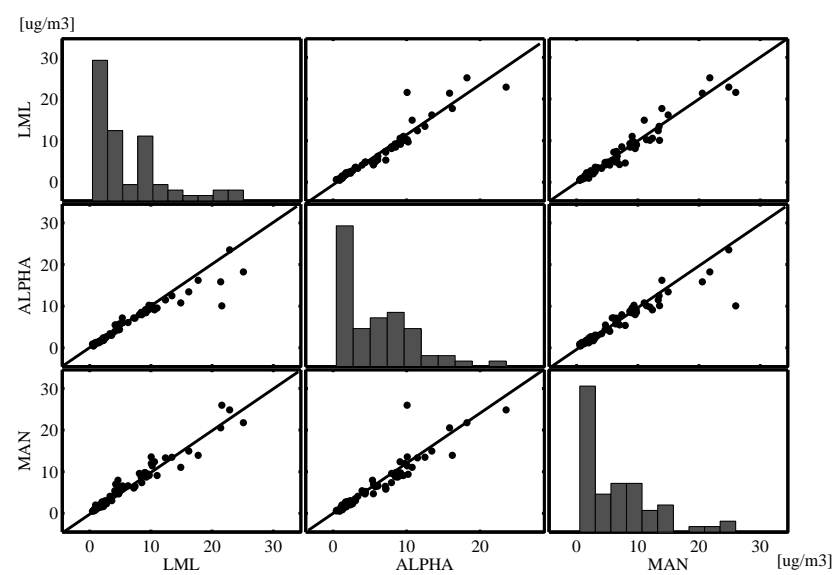

Figure 8. Scatter plots for the different combinations of LML, ALPHA, and MAN. The diagonal shows the histograms of the three data sets. 1-to-1 lines have been added for reference.

these 10 solutions is taken as the imputed value. The difference between the 10 cycles gives an estimate of the uncertainty of the imputation process.

The method has been tested in two ways. First, estimates for missing data were produced by expert judgement by using meteorological and local source information and compared with the imputed data. Second, data was deleted from the data set and imputed data were compared with the actual measured data. No large discrepancies were found either way.

\subsection{Uncertainty analysis}

The uncertainty in a single monthly MAN value has three components: (i) the random uncertainty of a single MAN measurement, (ii) the uncertainty of the calibration procedure, and (iii) the uncertainty of the calibration standard (i.e. the LML measurement). The random uncertainty of a single MAN measurement is determined by analysing the data of all non-reference triplicates that are operational since September 2011. The analysis is based on 694 SDs for mean values ranging from 0 to $20 \mu \mathrm{g} \mathrm{m}^{-3}$. The variance of the random uncertainty is described by a model that consists of a contribution that is independent of the concentration and a part that is proportional to the concentration. The parameters of the variance model are estimated using the maximum likelihood method and give a variance of $\left[0.35^{2}+\right.$ $\left.(0.16 \times \text { conc })^{2}\right] \mu \mathrm{g} \mathrm{m}^{-3}$. The random uncertainty is given as a SD and therefore the square root of the variance. The uncertainty of the calibration procedure is determined by the $\mathrm{SD}$ of the deviations of the calibration fit for all data since March 2007, giving an uncertainty in the monthly calibration fit of $8.2 \%$. To determine the random part of this uncertainty, we did the same analysis for a 3-month calibration and a yearly calibration, giving values of 4.8 and $0.64 \%$, respectively. Because of the steep decrease in uncertainty by in- 
Table 2. Overview of different uncertainties to be applied to the MAN data.

\begin{tabular}{|c|c|c|c|}
\hline $\begin{array}{l}\text { Uncertainties } \\
\left(\mathrm{in} \mu \mathrm{g} \mathrm{m}^{-3}\right)\end{array}$ & 1 month & 3-month average & Yearly average \\
\hline Standard uncertainty & {$\left[0.35^{2}+(0.20 \times \text { conc })^{2}\right]^{1 / 2}$} & {$\left[0.20^{2}+(0.13 \times \text { conc })^{2}\right]^{1 / 2}$} & {$\left[0.10^{2}+(0.096 \times \text { conc })^{2}\right]^{1 / 2}$} \\
\hline $\begin{array}{l}\text { Comparing data within one area; } \\
\text { only for small concentration differences }\end{array}$ & {$\left[0.35^{2}+(0.16 \times \text { conc })^{2}\right]^{1 / 2}$} & {$\left[0.20^{2}+(0.094 \times \text { conc })^{2}\right]^{1 / 2}$} & {$\left[0.10^{2}+(0.047 \times \text { conc })^{2}\right]^{1 / 2}$} \\
\hline $\begin{array}{l}\text { Comparing areas for } \\
\text { the same time period }\end{array}$ & {$\left[0.35^{2}+(0.18 \times \text { conc })^{2}\right]^{1 / 2}$} & {$\left[0.20^{2}+(0.10 \times \text { conc })^{2}\right]^{1 / 2}$} & {$\left[0.10^{2}+(0.052 \times \text { conc })^{2}\right]^{1 / 2}$} \\
\hline $\begin{array}{l}\text { Trend analysis for an } \\
\text { area with four locations }\end{array}$ & - & - & {$\left[0.051^{2}+(0.084 \times \text { conc })^{2}\right]^{1 / 2}$} \\
\hline
\end{tabular}

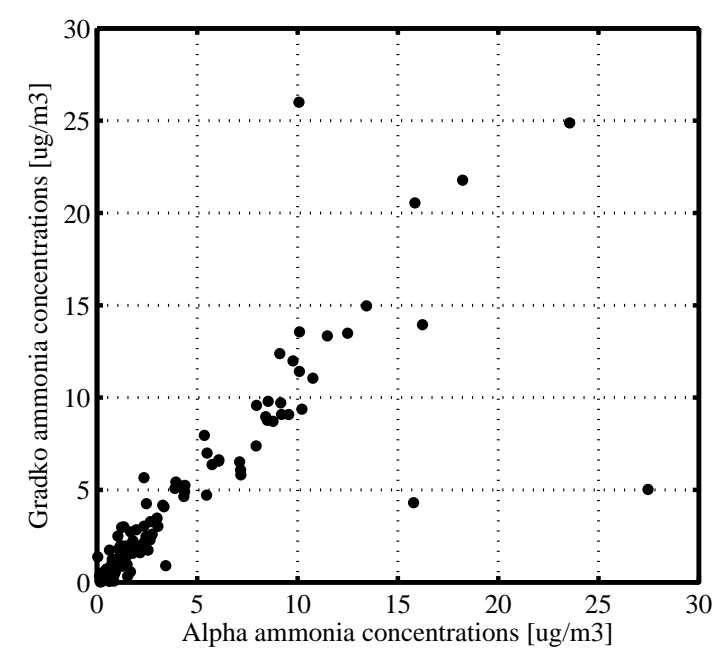

Figure 9. MAN ammonia concentrations compared to ALPHA ammonia concentrations for the LML stations De Zilk, Wieringerwerf, Zegveld and Wekerom in the period October 2010-December 2012, and for the Natura 2000 areas Zwanenwater and Meijendel for the period October 2011-December 2012. All data from Terschelling had to be rejected.

creasing the time period, we handle the uncertainty of the calibration procedure as being random. Lastly, the uncertainty of the calibration standard is more difficult to determine. The uncertainty in the LML-AMOR values for ammonia is $9.9 \%$ for hourly values and $6.7 \%$ for yearly values (Blank, 2001). With no more details available, we set the uncertainty of monthly values of LML-AMOR ammonia to $8 \%$. The uncertainty in the calibration standard is to be treated as a systematic uncertainty. Combining the three uncertainties gives an uncertainty in a single monthly MAN value of (Eq. 2)

$s_{\text {single MAN value }}$

$=\sqrt{\left[s_{\text {MAN measurement }}^{2}+s_{\text {calibration procedure }}^{2}+s_{\text {calibration standard }}^{2}\right]}$.

Averaging over time will decrease the random uncertainties, i.e. uncertainty (MAN measurement) and uncertainty (calibration procedure) with the square root of the number of measurements in the time period. When comparing data of different locations within one area, exposure conditions are assumed to be equal and the calibration uncertainty, i.e. the uncertainty in the calibration procedure and the uncertainty in the calibration standard can be omitted. This only applies for small concentration differences within an area. When comparing data of different areas, but for the same time period, the systematic uncertainty, i.e. the uncertainty in the calibration standard, can be omitted. When analysing trends over time for an area, the random uncertainties will decrease with the square root of the number of locations in the area, four on average. Trends over time will be analysed based on yearly averaged data. Table 2 gives an overview of the resulting uncertainties, and Table 3 gives some examples.

The median of the MAN measurements is $4.1 \mu \mathrm{g} \mathrm{m}^{-3}$. For this value, the standard uncertainty for a single monthly MAN measurement is $22 \%$. A typical relevant parameter is the trend over time for an area. For an area with four locations, the uncertainty in an area's yearly average of $4.2 \mu \mathrm{g} \mathrm{m}^{-3}$ is $8.5 \%$ for this trend analysis. This is very close to the uncertainty in the calibration standard, i.e. the systematic error indicating that the uncertainty of the individual measurements is quite effectively repressed by the number of measurements.

\subsubsection{Comparison with ALPHA passive samplers}

The uncertainty in a single MAN measurement, performed with Gradko $\mathrm{NH}_{3}$ passive samplers, is quite high for low concentrations: 41 and $27 \%$ for 1 and $2 \mu \mathrm{g} \mathrm{m}^{-3}$, respectively. To check the accuracy of Gradko $\mathrm{NH}_{3}$ passive sampler measurements for low concentrations, we compared them with passive samplers with a much higher uptake rate, the ALPHA (Adapted Low-cost Passive High Absorption; Tang et al., 2001) $\mathrm{NH}_{3}$ passive samplers. Hereto, we performed triplicate measurements with Gradko and ALPHA $\mathrm{NH}_{3}$ passive samplers at four LML locations for a period of more than 2 years. Measurements were performed at the LML-stations De Zilk, Wieringerwerf, Zegveld and Wekerom, locations with low to medium $\mathrm{NH}_{3}$ concentrations, in the period October 2010 December 2012. Triplicate means were used for the analysis. Correlation coefficients have been determined for the differ- 
Table 3. Examples of uncertainties in the MAN data for different ammonia concentrations. Cases comparing data within one area and comparing areas for the same time period are not shown.

\begin{tabular}{lrrrrrrrr}
\hline & \multicolumn{3}{c}{ Uncertainty absolute $\left(\mu \mathrm{g} \mathrm{m}^{-3}\right)$} & \multicolumn{3}{c}{ Uncertainty relative $(\%)$} \\
\cline { 2 - 9 } $\begin{array}{l}\text { Concentration } \\
\left(\mu \mathrm{g} \mathrm{m}^{-3}\right)\end{array}$ & 1 month & 3-month & Year & $\begin{array}{r}\text { Trend (year) area; } \\
\text { four locations }\end{array}$ & 1 month & 3-month & $\begin{array}{r}\text { Year } \\
\text { Trend (year) area; } \\
\text { four locations }\end{array}$ \\
\hline 1 & 0.41 & 0.24 & 0.14 & 0.10 & 41 & 24 & 14 & 9.8 \\
2 & 0.53 & 0.33 & 0.22 & 0.18 & 27 & 17 & 11 & 8.8 \\
5 & 1.1 & 0.69 & 0.49 & 0.42 & 21 & 14 & 9.8 & 8.5 \\
10 & 2.0 & 1.3 & 0.96 & 0.84 & 20 & 13 & 9.6 & 8.4 \\
20 & 4.0 & 2.6 & 1.9 & 1.7 & 20 & 13 & 9.6 & 8.4 \\
\hline
\end{tabular}

Table 4. Correlation coefficients for the different combinations LML, ALPHA, and MAN. The selection of MAN values smaller than $3 \mu \mathrm{g} \mathrm{m}^{-3}$ is shown as well.

\begin{tabular}{lcc}
\hline & \multicolumn{2}{c}{ Correlation coefficient } \\
& $\begin{array}{c}\text { All } \\
\text { (65 data pairs) }\end{array}$ & $\begin{array}{c}\text { MAN }<3 \mu \mathrm{g} \mathrm{m}^{-3} \\
\text { (25 data pairs) }\end{array}$ \\
\hline LML-ALPHA & 0.96 & 0.93 \\
LML-MAN & 0.97 & 0.84 \\
ALPHA-MAN & 0.93 & 0.81 \\
\hline
\end{tabular}

ent combinations LML, ALPHA, and MAN; see Fig. 8 and Table 4. A special selection has been made for MAN values smaller than $3 \mu \mathrm{g} \mathrm{m}^{-3}$; see Table 4 as well. MAN data were calibrated and validated as described before.

The correlation coefficients are high, also for low concentrations. Performing a first-order polynomial fitting of MAN against ALPHA data (bottom-middle panel in Fig. 8) gives a slope of $1.1(0.94)$ and an offset of $0.014(0.20)$. The numbers in parentheses give the values for the selection of MAN values smaller than $3 \mu \mathrm{g} \mathrm{m}^{-3}$. That is, the measurements with the ALPHA passive samplers confirm the accuracy of the MAN measurements.

ALPHA measurements also have been exploited in the Natura2000 areas of Terschelling, Zwanenwater and Meijendel (dune areas with low $\mathrm{NH}_{3}$ concentrations), where the monthly exchange of the passive samplers is performed by volunteers in the field. ALPHA samplers are much more difficult to exchange than Gradko passive samplers. The design of the ALPHA samplers makes it quite difficult to remove the protective cap without removing the porous filter as well. The difficulty of changing the samplers, as compared to Gradko passive samplers, immediately becomes apparent, as most of the measurements had to be rejected due to improper handling. Figure 9 shows the MAN data compared to ALPHA measurements for all data available (LML locations and Natura2000 locations).

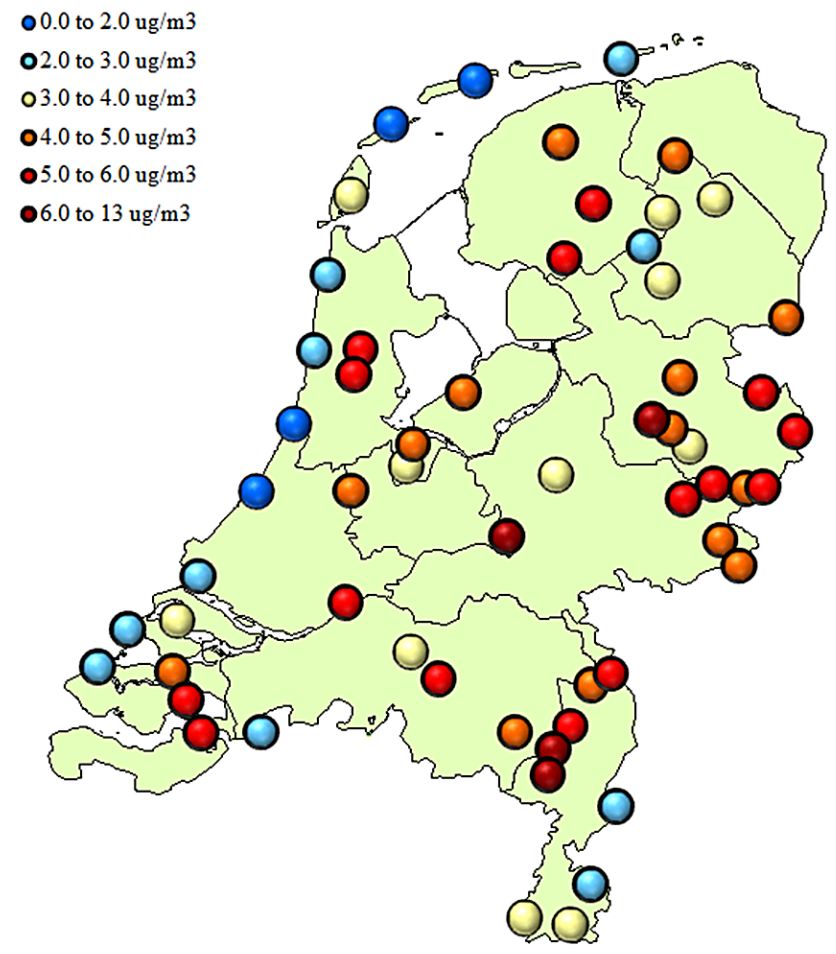

Figure 10. Area's yearly averages for the year 2013.

\subsection{Yearly averages}

MAN data is used for monitoring, analysing trends and model validation. Different aggregations of data are used, of which the yearly averaged values are the most important. To minimise the effect of missing data, the yearly averaged values are calculated using the imputed data set. A yearly value will consist of at least seven actually measured values. First of all, yearly averages for all locations are calculated. Then, the area's yearly average is calculated from the location's yearly averages. The MAN yearly average is either constructed from the mean of all yearly location averages or the mean of all yearly area averages. In a few cases, a location is not representative of the area, for example a location 


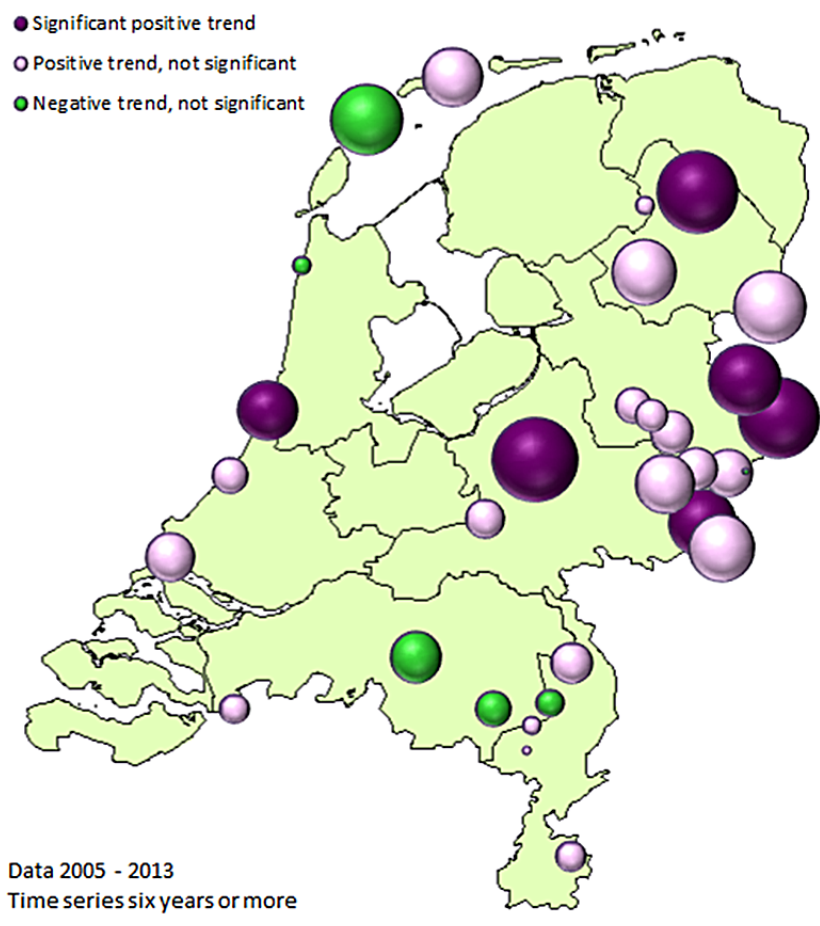

Figure 11. Trends in ammonia concentration over time for the MAN areas. The size of the dots corresponds with the size of the trend.

near a highway. In these cases, the location is excluded from the area and MAN average.

\section{Results and discussion}

We present the proof of concept of a monitoring network exploited with inexpensive sensors calibrated against a number of high-quality measuring devices. Over 200 inexpensive Gradko passive samplers for ammonia are calibrated monthly against six AMOR active measuring devices for ammonia. Based on a 6-year data set we find an uncertainty in yearly values of $\left[0.10^{2}+(0.096 \times \text { conc })^{2}\right]^{1 / 2} \mu \mathrm{g} \mathrm{m}^{-3}$. For the median value found in the MAN network of $4.1 \mu \mathrm{g} \mathrm{m}^{-3}$, this gives an uncertainty of $0.41 \mu \mathrm{g} \mathrm{m}^{-3}(9.9 \%)$ for yearly values. For one of the main goals of the MAN network, analysing trends over time for an area, the uncertainty in yearly values for an area with four locations is $\left[0.051^{2}+(0.084 \times \text { conc })^{2}\right]^{1 / 2} \mu \mathrm{g} \mathrm{m}^{-3}$, giving an uncertainty of $0.36 \mu \mathrm{g} \mathrm{m}^{-3}(8.5 \%)$ for a yearly value $4.2 \mu \mathrm{g} \mathrm{m}^{-3}$.

Passive samplers for ammonia have been analysed before for precision and accuracy (Thijsse et al., 1998; Thöni et al., 2003; Kirchner et al., 1999; Puchalski et al., 2011). None of these methods however uses the concept of a network of inexpensive sensors calibrated for each batch against a few high-quality measuring devices. This concept proofs a valuable method to monitor atmospheric ammonia concen-

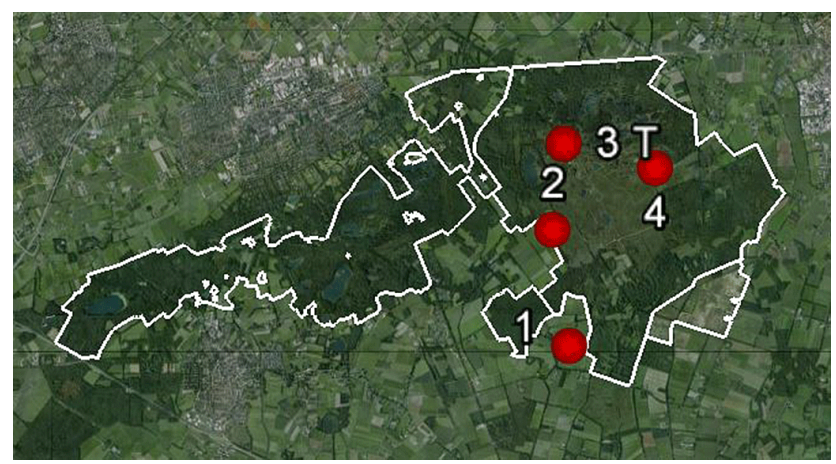

Figure 12. Map of the nature area of Kampina and the measurement locations. Location 1 is situated very close to a pig housing. Location 3 contains the triplicate measurement.

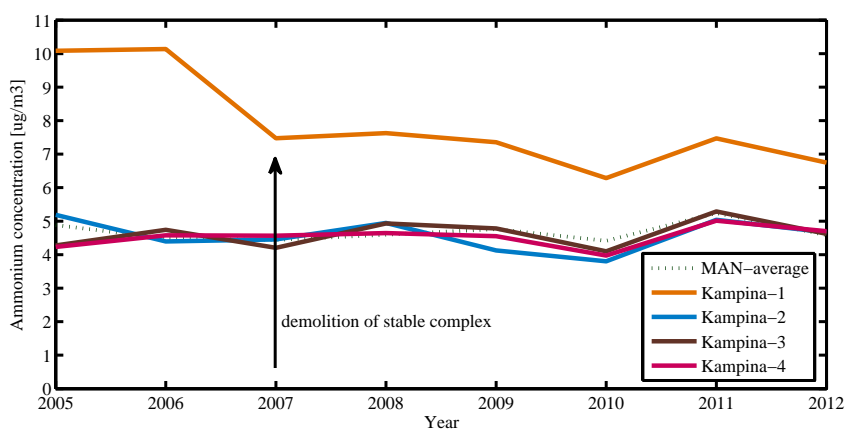

Figure 13. Yearly averaged location values for the ammonia concentration in the nature area of Kampina for the period 2005-2012. The yearly values for the MAN average are also shown. The black arrow shows the year in which the pig housing was dismantled. See locations in Fig. 12.

trations on a large scale. The following subsection shows some examples of analyses with MAN data.

\subsection{Area yearly averages}

Area yearly averages for the MAN network vary from 1.0 to $14 \mu \mathrm{g} \mathrm{m}^{-3}$, with a median value of $4.2 \mu \mathrm{g} \mathrm{m}^{-3}$. The lowest concentrations are found at the coastal locations, high concentrations are merely found in the east and south-east of the Netherlands. This corresponds with the emission pattern that is highest in the south-east and east of the Netherlands and low in the coastal regions. Figure 10 shows the area's yearly averages for the year 2013 .

\subsection{Trends}

To monitor atmospheric ammonia concentrations in nature areas in the Netherlands we look at trends over time in the yearly averaged measured concentrations. No significant increasing or decreasing trend is observed in the MAN average since its start in 2005. However, for six areas a significant increasing trend is observed. A trend is called significant if 
it deviates more than $2 \sigma$ from zero. Figure 11 shows the observed trend for the different areas. Trends are calculated for areas that started no later than 2008. The size of the dots corresponds with the size of the trend. The colours indicate if the observed trend is significantly positive, positive (not significant) or negative (not significant). Note that the trend for an area is susceptible to the selection of data used to calculate the area's yearly averages. The selection is a choice and may change, leading to changes in individual trends. However, the general picture over the Netherlands will remain the same.

\subsection{Area analysis}

Apart from regional trends, the MAN data can be used to analyse a local area in more detail. Here, we will give an example of the effect of the dismantling of a pig housing very close to the nature area of Kampina. Figure 12 shows the contours of the nature area of Kampina and the measurement locations. A pig housing was located $200 \mathrm{~m}$ west of point Kampina-1. This pig housing was dismantled in the spring of 2007 and in June 2007 a very high ammonia concentration was measured at point Kampina-1. After dismantling, ammonia concentrations at point Kampina-1 were much lower than before. Point Kampina-1 is located on the border of the nature area and close to some other animal housings. This explains the still higher ammonia concentration at this point compared to the other measurement locations in this nature area. Figure 13 shows the yearly values for the measurement locations in the area of Kampina.

\section{Conclusions}

We have shown that the MAN network is suitable for monitoring atmospheric ammonia concentrations in nature reserve areas over the Netherlands. The use of passive samplers combined with a monthly calibration against a high-quality sampling method and an extensive validation process significantly enhances the measurement accuracy. For yearly location averages we reach an accuracy of $\left[0.10^{2}+(0.096 \times \text { conc })^{2}\right]^{1 / 2} \mu \mathrm{g} \mathrm{m}^{-3}$. The quality of the network is such that trends over time for individual MAN areas can be detected on the order of $3 \%$ per year for time series of 6-9 years.

Edited by: X. Wang

\section{References}

Blank, F. T.: Meetonzekerheid Landelijk Meetnet Luchtkwaliteit (LML), KEMA 50050870-KPS/TCM 01-3063, Bilthoven, Netherlands Institute for Public Health and the Environment, 2831, 2001.

Carmichael, G. R., Ferm, M., Thongboonchoo, N., Woo, J.-H., Chan, L. Y., Murano, K., Viet, P. H., Mossberg, C., Bala, R.,
Boonjawat, J., Upatum, P., Mohan, M., Adhikary, S. P., Shrestha, A. B., Pienaar, S. J. J., Brunke, E. B., Chen, T., Jie, T., Guoan, D., Peng, L. C., Dhiharto, S., Harjanto, H., Jose, A. M., Kimani, W., Kirouane A., Lacaux, J.-P., Richard, S., Barturen, O., Cerda, J. C., Athayde, A., Tavares, T., Cotrina J. S., and Bilici, E.: Measurements of sulfur dioxide, ozone and ammonia concentrations in Asia, Africa, and South America using passive samplers, Atmos. Environ., 37, 1293-1308, 2003.

Dämmgen, U.: Atmospheric nitrogen dynamics in Hesse, Germany: Creating the data base 3, Monitoring of atmospheric concentrations of ammonia using passive samplers, Landbauforschung Völkenrode, 3, 247-254, 2007.

European Commision: Habitats Directive, 92/43/EEC, Brussels, 1992.

European Commision: Birds Directive, 2009/147/EC, Brussels, 2009.

Geman, S. and Geman, D.: Stochastic Relaxation, Gibbs Distributions, and the Bayesian Restoration of Images, IEEE T. Pattern. Anal., 6, 721-741, 1984.

Gradko: available at: http://www.gradko.com/environmental/ products/ammonia.shtml, last access: 17 February 2015.

Hoogerbrugge R. and Liem, A. K. D.: How to handle non-detects, Organohalogen Compounds, 45, 13-16, 2000.

Kirchner, M., Braeutigam, S., Ferm, M., Haas, M., Hangartner, M., Hofschreuder, P., Kasper-Giebl, A., Römmelt, H., Striedner, J., Terzer, W., Thöni, L., Werner, H., and Zimmerling, R.: Field intercomparison of diffusive samplers for measuring ammonia, J. Environ. Monitor., 1, 259-265, 1999.

Natura 2000: available at: http://ec.europa.eu/environment/nature/ natura2000/index_en.htm, last access: 17 February 2015.

PAS: available at: Pas.natura2000.nl, last access: 26 January 2015.

Puchalski, M. A., Sather, M. E., Walker, J. T., Lehmann, C. M. B., Gay, D. A., Mathew, J., and Robarge, W. P.: Passive ammonia monitoring in the United States: Comparing three different sampling devices, J. Environ. Monitor., 13, 3156-3167, 2011.

Tang, Y. S., Cape, J. N., and Sutton, M. A.: Development and types of passive samplers for monitoring atmospheric NO2 and NH3 concentrations, Proceedings of the International Symposium on Passive Sampling of Gaseous Air Pollutants in Ecological Effects Research, TheScientificWorld, 1, 513-529, 2001.

Thijsse, T. R., Duyzer, J. H., Verhagen, H. L. M., Wyers, G. P., Wayers, A., and Möls, J. J.: Measurement of ambient ammonia with diffusion tube samplers, Atmos. Environ., 32, 333-337, 1998.

Thöni, L., Seitler, E., Blatter, A., and Neftel, A.: A passive sampling method to determine ammonia in ambient air, J. Environ. Monitor., 5, 96-99, 2003.

van Elzakker, B. G.: Monitoring activities in the Dutch National Air Quality Monitoring Network in 2000 and 2001, Report 723101055, RIVM Bilthoven, 2001.

van Jaarsveld, J. A.: The Operational Priority Substances model, Description and validation of OPS-Pro 4.1, Report 500045001 , RIVM Bilthoven, 2004.

van Pul, A., van Jaarsveld, H., van der Meulen, T., and Velders, G.: Ammonia concentrations in the Netherlands: spatially detailed measurements and model calculations, Atmos. Environ., 38, 4045-4055, 2004.

Velders, G. J. M., Aben, J. M. M., van Jaarsveld, J. A., van Pul, W. A. J., de Vries, W. J., and van Zanten, M. C.: Grootschalige stik- 
stofdepositie in Nederland, Report 500088007, PBL Bilthoven, 15-19, 2010.

Wilson, S. M. and Serre, M. L.: Use of passive samplers to measure atmospheric ammonia levels in a high-density industrial hog farm area of eastern North Carolina, Atmos. Environ., 41, 60746086, 2007.
Zbieranowski, A. L. and Aherne, J.: Ambient concentrations of atmospheric ammonia, nitrogen dioxide and nitric acid in an intensive agricultural region, Atmos. Environ., 70, 289-299, 2013. 